\title{
Surgical Treatment for Gastroesophageal Reflux Disease: Is It Effective Even for Asians?
}

\author{
Chan Hyuk Park
}

Department of Internal Medicine, Hanyang University Guri Hospital, Hanyang University College of Medicine, Guri, Korea

\begin{abstract}
Article: Multicenter prospective study of laparoscopic Nissen fundoplication for gastroesophageal reflux disease in Korea Park S, Park J, Kim J, et al

(J Neurogastroenterol Motil 2019;25:394-402)
\end{abstract}

Gastroesophageal reflux disease (GERD) is a prevalent disease worldwide, and its prevalence is the highest in North America (18.1-27.8\%). ${ }^{1}$ The prevalence of GERD is low in East Asia (2.5$7.8 \%) ;{ }^{1}$ however, it is gradually increasing in this region. ${ }^{2-5} \mathrm{Al}-$ though various treatment options are available, proton pump inhibitors (PPIs) are still a mainstay in the management of patients with GERD. An approximately 70\% healing rate and 60-90\% complete symptom relief rate can be achieved by 4 weeks of PPI medication in patients with erosive reflux disease. ${ }^{6}$ The guidelines in the United States strongly recommend an 8-week course of PPIs as the therapy of choice for symptom relief and healing of erosive esophagitis. ${ }^{7}$

However, medical treatment of GERD has clinically unmet needs. First, GERD impairs patients' quality of life and work productivity despite antireflux medications. ${ }^{8,9}$ Refractory GERD symptoms have been identified in $10-40 \%$ of patients with GERD who are treated with PPIs. ${ }^{10,11}$ The economic burden due to longterm medication is also a concern. ${ }^{11}$ In recent years, potential adverse events, including bone fracture, Clostridium difficile infection, pneumonia, micronutrient deficiency, dementia, and chronic kidney disease, have been suggested in patients with chronic PPI use. ${ }^{12} \mathrm{~A}$ study even showed that PPI administration may be related to the development of gastric cancer, ${ }^{13}$ although several critical biases in the study were raised. ${ }^{14}$

Now that more than 40 years have passed since PPIs began to be used, it is time to consider another treatment for GERD, such as antireflux surgery. In fact, Nissen fundoplication, a representative surgical treatment for GERD, is not a novel treatment. It was first performed in 1955 by Rudolph Nissen. ${ }^{15}$ In Nissen fundoplication, the fundus is wrapped around the lower esophagus. This procedure tightens up the valve and closes off the esophagus whenever the stomach contracts. It is now usually performed laparoscopically since laparoscopic Nissen fundoplication was first described by Dallemagne et $\mathrm{al}^{16}$ in 1991. The efficacy of laparoscopic antireflux surgery has been found to be comparable with that of PPIs in a multicenter randomized trial conducted in Europe. ${ }^{17}$ In the study, the estimated 5-year remission rate in patients who had undergone laparoscopic antireflux surgery was 85\% (95\% confidence interval, $81-90 \%) .{ }^{17}$ Although the study enrolled only PPI responders, longterm results are promising because most patients who had undergone surgery could discontinue medications, including PPIs.

In this issue of the Journal of Neurogastroenterology and Motility, Park et $\mathrm{al}^{18}$ reported a multicenter prospective study on the

Received: June 24, 2019 Revised: None Accepted: July 8, 2019

() This is an Open Access article distributed under the terms of the Creative Commons Attribution Non-Commercial License (http://creativecommons. org/licenses/by-nc/4.0) which permits unrestricted non-commercial use, distribution, and reproduction in any medium, provided the original work is properly cited.

*Correspondence: Chan Hyuk Park, MD, PhD Department of Internal Medicine, Hanyang University Guri Hospital, Hanyang University College of Medicine, 153 Gyeongchun-ro, Guri 11923, Korea

Tel: +82-31-560-2230, Fax: +82-31-553-7369, E-mail: yesable7@gmail.com 
efficacy of laparoscopic Nissen fundoplication for GERD in Korea. In the study, antireflux surgery was found to significantly improve GERD symptoms and quality of life in patients with GERD indicated for surgical treatment. This study is clinically important for 3 reasons. First, it was performed in Korea, where most patients with GERD are currently treated with medication rather than surgery. Therefore, most patients had undergone long-term PPI therapy before surgery. The median follow-up duration of PPI therapy was 61.5 months, and 27\% of patients took PPIs for more than 10 years. Nevertheless, more than $70 \%$ of patients did not require any medication at 3 months after the surgery. Second, the study population included relatively low proportions of severe erosive reflux disease (Los Angeles grade B-D, 13\%), hiatal hernia (33\%), and obese patients (35\%). These study populations have distinct characteristics from those of patients with GERD in Western countries, including those with severe erosive reflux disease, hiatal hernia, and obesity. Thus, this study shows that antireflux surgery may be useful even in Asian populations. Third, this study also included many poor or non-responders to acid-suppressive drugs (49\%). As most patients had typical symptoms (94\%), including heartburn and regurgitation, we can guess that patients with symptoms caused by weakly acidic or non-acidic reflux may be included in the study. ${ }^{19}$ On the basis of the study findings, we can consider surgical treatment even for patients with typical symptoms but who do not respond to PPI therapy, in addition to patients who respond to PPI therapy.

As the authors already stated, the study by Park et a ${ }^{18}$ has a limitation of reporting only short-term outcomes of laparoscopic Nissen fundoplication. Nevertheless, this study, which included the largest prospective cohort in Korea, may provide a better understanding of the efficacy of laparoscopic Nissen fundoplication in East Asian patients with GERD. In the near future, long-term follow-up of this cohort will lead to a new perspective on the treatment of patients with GERD, especially in Asian countries.

\section{Financial support: None.}

\section{Conflicts of interest: None.}

Author contributions: Chan Hyuk Park drafted, revised, and approved the manuscript.

\section{References}

1. El-Serag HB, Sweet S, Winchester CC, Dent J. Update on the epide- miology of gastro-oesophageal reflux disease: a systematic review. Gut 2014;63:871-880.

2. Wang FW, Tu MS, Chuang HY, Yu HC, Cheng LC, Hsu PI. Erosive esophagitis in asymptomatic subjects: risk factors. Dig Dis Sci 2010;55:1320-1324.

3. Chen MJ, Lee YC, Chiu HM, Wu MS, Wang HP, Lin JT. Time trends of endoscopic and pathological diagnoses related to gastroesophageal reflux disease in a Chinese population: eight years single institution experience. Dis Esophagus 2010;23:201-207.

4. Hung LJ, Hsu PI, Yang CY, Wang EM, Lai KH. Prevalence of gastroesophageal reflux disease in a general population in Taiwan. J Gastroenterol Hepatol 2011;26:1164-1168.

5. Chang FY. Variations in the reported prevalence of gastroesophageal reflux disease in Taiwan. J Chin Med Assoc 2012;75:91-92.

6. Chiba N, De Gara CJ, Wilkinson JM, Hunt RH. Speed of healing and symptom relief in grade II to IV gastroesophageal reflux disease: a metaanalysis. Gastroenterology 1997;112:1798-1810.

7. Katz PO, Gerson LB, Vela MF. Guidelines for the diagnosis and management of gastroesophageal reflux disease. Am J Gastroenterol 2013;108:308-328.

8. Wang R, Zou D, Ma X, et al. Impact of gastroesophageal reflux disease on daily life: the systematic investigation of gastrointestinal diseases in China (SILC) epidemiological study. Health Qual Life Outcomes 2010;8:128.

9. Gross M, Beckenbauer U, Burkowitz J, Walther H, Brueggenjuergen B. Impact of gastro-oesophageal reflux disease on work productivity despite therapy with proton pump inhibitors in Germany. Eur J Med Res 2010;15:124-130.

10. Niu XP, Yu BP, Wang YD, et al. Risk factors for proton pump inhibitor refractoriness in Chinese patients with non-erosive reflux disease. World J Gastroenterol 2013;19:3124-3129.

11. Lee ES, Kim N, Lee SH, et al. Comparison of risk factors and clinical responses to proton pump inhibitors in patients with erosive oesophagitis and non-erosive reflux disease. Aliment Pharmacol Ther 2009;30:154164

12. Freedberg DE, Kim LS, Yang YX. The risks and benefits of long-term use of proton pump inhibitors: expert review and best practice advice from the American gastroenterological association. Gastroenterology 2017;152:706-715.

13. Cheung KS, Chan EW, Wong AYS, Chen L, Wong ICK, Leung WK. Long-term proton pump inhibitors and risk of gastric cancer development after treatment for Helicobacter pylori: a population-based study. Gut 2018;67:28-35.

14. Suissa S, Suissa A. Proton-pump inhibitors and increased gastric cancer risk: time-related biases. Gut 2018;67:2228-2229.

15. Nissen R. [A simple operation for control of reflux esophagitis]. Schweiz Med Wochenschr 1956;86(suppl 20):590-592.[German]

16. Dallemagne B, Weerts JM, Jehaes C, Markiewicz S, Lombard R. Laparoscopic nissen fundoplication: preliminary report. Surg Laparosc Endosc 1991;1:138-143.

17. Galmiche JP, Hatlebakk J, Attwood S, et al. Laparoscopic antireflux surgery vs esomeprazole treatment for chronic GERD: the LOTUS 
randomized clinical trial. JAMA 2011;305:1969-1977.

18. Park S, Park J, Kim J, et al. Multicenter prospective study of laparoscopic Nissen fundoplication for gastroesophageal reflux disease in Korea. J
Neurogastroenterol Motil 2019;25:394-402.

19. Zaninotto G, Attwood SE. Surgical management of refractory gastrooesophageal reflux. Br J Surg 2010;97:139-140. 